\title{
Reinke's Oedema Presenting as Stridor: Implications for Otolaryngologists in Difficult Airway
}

\author{
Atta Mohyuddin, Gurpeet Sandhu \\ Charing Cross Imperial College Hosp, London, UK \\ Email:atai_1999@yahoo.com
}

How to cite this paper: Mohyuddin, A. and Sandhu, G. (2017) Reinke's Oedema Presenting as Stridor: Implications for Otolaryngologists in Difficult Airway. International Journal of Otolaryngology and Head \& Neck Surgery, 6, 11-15. https://doi.org/10.4236/ijohns.2017.62003

Received: March 1, 2015

Accepted: February 21, 2017

Published: February 24, 2017

Copyright $\odot 2017$ by authors and Scientific Research Publishing Inc. This work is licensed under the Creative Commons Attribution International License (CC BY 4.0).

http://creativecommons.org/licenses/by/4.0/ (c) (i) Open Access

\begin{abstract}
We demonstrated the importance of managing a patient who presented with stridor due to severe Reinke's oedema. The concept of managing difficult airway has thus been introduced for the otolaryngologists according to a plan of action as described by the American Society of Anaesthesiologist's difficult airway algorithm. Methods: A case report of interest and review of literature. PubMed search with keywords of difficult airway, stridor, awake intubation and Reinke's oedema was used. Result: Management of an anticipated difficult airway with awake fiberoptic intubation with backup strategies of direct laryngoscopies with Eshmann stylet and awake invasive intubation is highlighted. Conclusion: This case report demonstrated a definitive strategy of securing a difficult airway with obstruction at the glottis and highlighted the role of teamwork between otolaryngologist and anaesthesiologist to secure difficult airway.
\end{abstract}

\section{Keywords}

Reinke's Oedema, Stridor, Difficult Airway and Micro Laryngeal Surgery

\section{Introduction}

Reinke's oedema is fluid collection in the lamina propria of the true vocal cords, which is one of the five layers, deep to the squamous epithelial layer, and superficial to the superficial layer of the lamina propria of the true vocal fold [1]. The most common presentation is a middle-aged female who smokes and complains of hoarseness of voice [2]. Less commonly the patient may be dyspnoeic [2]. In this report, we describe a difficult airway case with Reinke's oedema involving the vocal cords especially the left vocal cord which has formed a sac like collection. The polypoidal like mass would fall into the sub-glottis space on inspiration 
causing stridor due to ball valve effect. We demonstrated this unusual presentation with stridor and highlighted the use of fiber optic intubation for securing the supra-glottic airway and then performing the micro laryngeal surgery as a joint team effort between the otolaryngologist and anaesthesiologist. The otolaryngologist should be aware of the anticipated difficult airway and bring in the necessary skills of using fiber optic intubation, more recently video-laryngoscopy, different laryngoscopes, rigid bronchoscopes or surgical tracheostomy as necessary techniques for securing the difficult airway.

\section{Case Study}

A 60-year-old female presented with three day history of worsening dyspnea, stridor and cough. On further inquiry she had been suffering from a fluctuant hoarseness for considerable time and recently became more dyspnoeic after short excursions. She was a heavy smoker and drank alcohol occasionally. Her past medical history included hypertension and gastro-esophageal reflux disease, but she was not on any medication. There was no family history of similar voice or respiratory problems, and she denied any weight loss. Her body mass index was 36 .

On examination, she was stridulous, tachycardiac (pulse 99 beats per minute), tachypnoeic (respiratory rate 28 breaths per minute) but was maintaining her oxygen saturation at $96 \%$ on room air. She was apyrexial and there was an immediate need for securing her anticipated difficult airway. She was given Heliox initially which stabilized her airway. Bloods results showed a raised pCO2 of 6.6 but normal $\mathrm{pH}$ and base excess on arterial blood analysis. Her Chest X-Ray demonstrated an element of heart failure with cardiomegaly.

Flexible laryngoscopy showed that both true vocal cords were grossly oedematous asymmetrically. On the left the edema had formed a small fluid collection which was attached to the vocal cord that was acting in a ball-valve fashion; it would fall into the subglottic area as the patient took a breath in, explaining the stridor and dyspnea.

A decision for awake intubation was made after consenting the patient and telling her the alternatives like surgical tracheostomy, so otolaryngologists were ready. On the day of admission the patient was taken to the operating room. The nasal mucosa was sprayed with phenylephrine and lidocaine $2 \%$. After sedation with midazolam and remifentanyl, the upper airway was secured by passing a size 6 Mallinckrodt reinforced tracheostomy tube mounted on a flexible bronchoscope. The patient maintained her saturations throughout the procedure. $\mathrm{Mi}$ crolaryngoscopy was used to confirm the preoperative findings, showing the mucosal sac obstructing the supra-glottic airway (Figure 1). After securing the airway, the mucosa of both vocal cords was incised, and the underlying fluid was suctioned, with replacement of the rest of the mucosa, resulting in a patent and safe airway for the patient. Histopathological analysis confirmed the clinical diagnosis of bilateral Reinke's oedema without evidence of malignancy. Post-operatively the patient recovered uneventfully. 


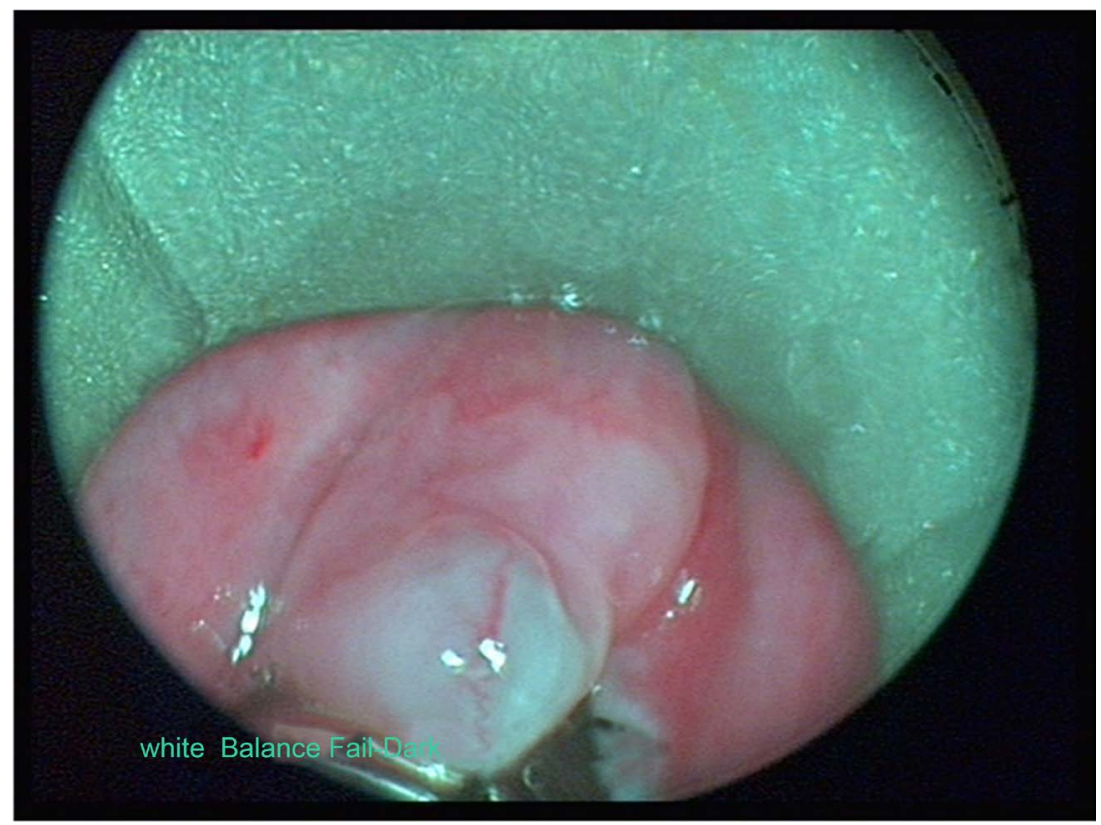

Figure 1. View at microlaryngoscopy demonstrating gross Reinke's edema.

\section{Discussion}

Difficult airway is defined as difficulty in ventilation, intubation and laryngoscopy by a trained anaesthesiologist. This entails difficulty in mask ventilation and difficulty in laryngoscopy and intubation due to various reasons and pathologies encountered. The case described show an anticipated difficult airway with stridor with severe Reinke's oedema which was an airway emergency. The case demonstrated that effective communication should be necessary for the best outcome of stridulous patient's presenting with difficult airway in a multidisciplinary setting. The strategy should be clear and both the otolaryngologist and anaesthesiologists should have a backup strategy for any problems encountered during the difficult airway scenarios [3] [4].

Reinke's space was first described as a potential space between the squamous epithelium of the vocal cord medially and the elastic tissue of the vocal ligament laterally [5]. The transition from squamous to columnar epithelium occurs at the junction between the superior and inferior borders of Reinke's space, namely the superior and inferior arcuate lines respectively. This space is normally filled with a thin layer of fluid which allows the vocal cord to flexibly vibrate during phonation as evident on videostroboscopy [2].

It is postulated that due to lack of a lymphatic drainage and repeated inflammation, results in accumulation of blood within this space [6]. The blood together with the ensuing tissue reaction causes the oedema [6]. Various different insults have been attributed to cause this. Smoking is considered a strong risk factor as $90 \%$ of patients have a smoking history [5]. Other common risk factors are voice abuse, irritants such as oil fumes and acid from reflux disease [5] [6]. Our patient had been smoking for many years and suffered reflux disease for which she had not been treated. 
Reports have shown that Reinke's oedema has a predilection for females, but this could be due to the change in voice to a harsh, masculine-like voice which will more likely prompt the female patient to seek medical attention sooner [5] [6]. It has a peak incidence in the fourth and fifth decade of life [2] [5] [6]. Apart from the usual complaint of change in voice tone, patients may present with dyspnea, pain or a lump in the throat but rarely with stridor [6].

The mainstay of treatment depends on the severity of the oedema and patient's symptoms. If the oedema is mild, patients should abstain from any precipitating factors like smoking, should be treated for reflux disease and advised to rest their voice and have sessions of speech therapy [6]. If the symptoms are more severe, and not amenable to speech therapy and vocal hygiene, the patient may require surgery in rare cases for biopsy to rule out potential for malignancy in chronic smokers [7] [8]. Two techniques have been described: 1) Stripping of the vocal folds to reveal the underlying Reinke's space, with suctioning of the fluid causing the edema and replacement of the vocal cord epithelium [9]; 2) the "squeezing technique" as described by Yonekawa et al. [2]. This patient underwent combination of the two with micro dissection of the mucosa laterally to access and then squeezing of the fluid by using adrenaline soaked patties and biopsy specimen was carried out. The patient had good resolution of her symptoms. Both procedures should be followed by abstinence from the precipitating factors and voice rehabilitation. The patients that continued to smoke after treatment were more likely to suffer recurrences [8]. The main risk factor for recurrence and histologic changes is the prolonged duration of tobacco. In one study by Pezone et al. 2002, found carcinoma in situ in $2.5 \%$ of patients presenting with bilateral Reinke's oedema [7]. Therefore biopsies are recommended especially in chronic smokers [7] [8]. Patients with Reinke's oedema pose a potential problem during intubation or after long term side effect of intubation [10] [11]. Our patient had an awake fiber optic intubation, so allowing her to maintain and secure airway as a first step of a difficult airway algorithm. A case has been previously described of difficult intubation when the anesthetist was unaware of the presence of a reinke's oedema [12], who was admitted for non-vocal cord surgery.

\section{Conclusion}

At the conclusion of this paper, the readers should be able to know that teamwork between otolaryngologist and anaesthesiologist in anticipated difficult airway is a crucial step in the management of the difficult airway in the otolaryngology patients presenting with stridor.

\section{References}

[1] Hirano, M. (1977) Structure and Vibratory Behavior of the Vocal Folds. In: Sawashimu, T. and Cooper, F. Eds., Dynamic Aspects of Speech Production, 13-27.

[2] Yonekawa, H. (1988) A Clinical Study of Reinke's Edema. Auris Nasus Larynx, 15, 57-78.

[3] American Society of Anesthesiologists Task Force on Management of the Difficult 
Airway (2003) Practice Guidelines for Management of the Difficult Airway: An Updated Report by the American Society of Anesthesiologists Task Force on Management of the Difficult Airway. Anesthesiology, 98, 1269-1277. https://doi.org/10.1097/00000542-200305000-00032

[4] American Society of Anesthesiologists Task Force on Management of the Difficult Airway (2013) Practice Guidelines for Management of the Difficult Airway. Anesthesiology, 118, 251-270. https://doi.org/10.1097/ALN.0b013e31827773b2

[5] Remenar, E., Elo, J. and Frint, T. (1984) The Morphological Basis for Development of Reinke's Oedema. Acta Oto-Laryngologica, 97, 169-176. https://doi.org/10.3109/00016488409130977

[6] Freedman, S.F. and Amedee, R.G. (1990) Reinke's Edema. The Journal of the Louisiana State Medical Society, 142, 7-9.

[7] Marcotullio, D., Magliulo, G. and Pezone, T. (2002) Reinke's Edema and Risk Factors: Clinical and Histopathologic Aspects. American Journal of Otolaryngology, 23, 81-84. https://doi.org/10.1053/ajot.2002.30961

[8] Moesgaard, N.V., Hojslet, P.E. and Palvio, D. (1986) Reinke's Oedema: A Premalignant Condition? The Journal of Laryngology \& Otology, 100, 1159-1162. https://doi.org/10.1017/S0022215100100751

[9] Nielsen, V.M., Hojslet, P.E. and Karlsmose, M. (1986) Surgical Treatment of Reinke's Oedema (Long-Term Results). The Journal of Laryngology \& Otology, 100, 187-190. https://doi.org/10.1017/S0022215100098959

[10] Basaranoglu, G., Erden, V., Kokten, N., Verim, A., et al. (2006) Laryngeal Web as a Result of Reinke's Oedema: A Cause of Difficult Endotracheal Intubation. British Journal of Anaesthesia, 96, 406-407. https://doi.org/10.1093/bja/aei643

[11] d'Hulst, D., Butterworth, J., Dale, S., et al. (2004) Polypoid Hyperplasia of the Larynx Misdiagnosed as a Malpositioned Laryngeal Mask Airway. Anesthesia \& Analgesia, 99, 1570-1572. https://doi.org/10.1213/01.ANE.0000134802.08319.CF

[12] Moorthy, S.S., Gupta, S. and Pfefferkorn, T. (2005) Anesthetic Implications of Reinke's Edema of Vocal Cords. Canadian Journal of Anesthesia, 52, 775-776. https://doi.org/10.1007/BF03016575

\section{Submit or recommend next manuscript to SCIRP and we will provide best service for you:}

Accepting pre-submission inquiries through Email, Facebook, LinkedIn, Twitter, etc. A wide selection of journals (inclusive of 9 subjects, more than 200 journals)

Providing 24-hour high-quality service

User-friendly online submission system

Fair and swift peer-review system

Efficient typesetting and proofreading procedure

Display of the result of downloads and visits, as well as the number of cited articles

Maximum dissemination of your research work

Submit your manuscript at: http://papersubmission.scirp.org/

Or contact ijohns@scirp.org 